\title{
Research on the Influence Path of Equity Pledge on Enterprise Value-Taking SMEs as an Example
}

\author{
Jueming Wang ${ }^{1, *}$ and Baobao $\mathrm{Li}^{1}$ \\ ${ }^{1}$ School of Economics and Management, Nanjing University of Aeronautics and Astronautics, Nanjing, Jiangsu 210016, \\ China \\ *Corresponding author.Email:810880544@qq.com
}

\begin{abstract}
In this paper, we use the structural equation model to analyze the influence path of the pledge of the largest shareholder on the value of the company. The study shows that the degree and scale of the pledge have different effects on the company value, but the total effect is positive. The results show that the equity pledge is beneficial to promoting the company's value. From the specific path, the direct action path plays a major role. In the indirect action path, the separation of the two rights, the financial risk and the enterprise innovation path, significantly impact the enterprise value. Still, the path of market value management has no significant effect on enterprise value.
\end{abstract}

Keywords: equity pledge, enterprise value, influence path, structural equation model

\section{INTRODUCTION}

At present, there is no consensus in academic circles on the impact of equity pledges on corporate value, and research findings are mainly classified as: negative correlation[1][2], positive correlation[3][4][5] and non-linear correlation[6][7] And very few scholars have conducted research on the impact paths of the economic consequences brought about by equity pledges. Existing studies mainly contain research on the impact paths of equity pledges on corporate financial risk, corporate performance, corporate valuation and corporate value, and the impact paths are mainly developed from three dimensions: the degree of separation of powers, market value management and corporate $R \& D$ investment, with relatively similar research perspectives.

This study aims to provide countermeasures and suggestions for corporate managers to improve corporate governance structures, external investors to make scientific and reasonable investment decisions, and regulators to improve regulatory mechanisms. Controlling shareholders have different motives for pledging their shares, including "emptying out" and raising funds to support corporate development.

\section{RESEARCH HYPOTHESIS}

\subsection{Separation of Powers}

The separation of the two rights will inevitably aggravate the agency problems of the enterprise, including the agency problems of shareholders and managers, the agency problems of major shareholders and small and medium shareholders, and the agency problems of shareholders and creditors. After the pledge of shares, the majority shareholder has an incentive to use its control for its own personal benefit, thus encroaching on the interests of small and medium shareholders and creditors, etc. Academics refer to the act of using control to encroach on the interests of small and medium shareholders as "tunnel digging", the key to which lies in the concealment of the act..

For SMEs, they face a lower level of regulation compared to state-owned enterprises, which provides a certain degree of convenience for controlling shareholders to engage in profit hollowing; on the other hand, SMEs are in the formative stage of their life cycle and face many investment and development opportunities, and the long-term benefits brought by development are immeasurable. Will it be a matter of "picking up sesame seeds and losing the watermelon"?

As a result, Hypothesis 1: The pledge of controlling shareholders' equity affects corporate value through the separation of two rights.

\subsection{Market Value Management}

Another important risk faced by controlling shareholders after pledging their shares is the risk of transfer of control brought by the downward movement of the share price. Specifically, once the share price of an enterprise falls to the warning line or the closing line, the pledging shareholder may need to call the margin, which brings pressure on the enterprise to call the margin. This may affect the management of the enterprise and may also result in a transfer of control of the enterprise.

Shareholders tend to reduce the possibility of share price collapse through market capitalisation management in order to avoid the risk of control transfer. Market 
capitalisation management is a long-term organisational mechanism established to maximise corporate value, consisting of value creation, value realisation and value management. The ways in which companies conduct market capitalisation management include equity incentives and improving corporate governance structures. However, the market value management conducted by many enterprises is not value management in the actual sense, but share price manipulation through surplus management, share buybacks and selective information disclosure under the guise of market value management, which is an opportunistic behaviour of controlling shareholders does not lead to actual enhancement of corporate value, and the risk of share price collapse rises and corporate value declines after the end of equity pledges.

SMEs are relatively small in size and less able to withstand the risks associated with share price volatility, so they use market capitalization as a means of stabilising their share prices.

As a result, Hypothesis 2: Controlling shareholder equity pledges affect corporate value through market value management is proposed.

\subsection{Financial Risks}

The causes of financial risk in SMEs are both internal business reasons and external market environment. SMEs are more vulnerable to financial risks than large enterprises due to their small size and single business operation, and it is more difficult to turn financial risks into opportunities.

On the one hand, changes in the business activities and operating environment of the enterprise will have an impact on the financial risk faced by the enterprise after the controlling shareholder's shareholding is pledged, and on the other hand, although this form of financing does not have the same pressure of debt financing in terms of capital repayment, the pressure of margin call brought about by a fall in the share price also exacerbates the financial risk faced by the enterprise to a certain extent.

This leads to Hypothesis 3: Controlling shareholder equity pledges affect firm value through financial risk.

\subsection{Corporate Innovation}

The thriving innovation capacity of SMEs in their formative years is a core competency. The innovation theory proposed by economist Schumpeter emphasises the native drive and centrality of innovation. Studies have found that after controlling shareholders make equity pledges, their capital investment mainly includes the enterprises corresponding to the pledged shares, the shareholders themselves and other third parties, with significant differences in the economic consequences of different capital investment. For shareholders of SMEs, using the funds obtained from pledges to support their own development, increase their investment in research and development, and address the funds needed for their development and innovation will fundamentally enhance the intrinsic motivation for innovation.

However, it is undeniable that innovation returns are highly uncertain and have a long lag time remains a question of whether major shareholders will, on balance, invest pledged funds in corporate innovation activities.

This leads to Hypothesis 4: Controlling shareholder equity pledges affect firm value through innovation capability.

\section{EMPIRICAL STUDIES}

\subsection{Sample Selection}

This study takes SMB enterprises as the main subject of study, and selects enterprises (a total of 177) that all carry out equity pledges from 2015-2019 for the study. After excluding ST enterprises and enterprises with missing data, a total of 599 research samples are obtained.

The data for this article was obtained from the WAND database and the Guotaian database.

\subsection{Variable Selection}

Table 1. Variable design and calculation method

\begin{tabular}{|c|c|c|}
\hline Variables & Symbol & Calculation \\
\hline Pledge of equity & Pledge1 & Proportion of pledged shares to shareholders' holdings \\
\hline & Pledge2 & Proportion of pledged shares to the company's total equity \\
\hline Separation of powers & Separate & Control-Ownership \\
\hline Market value management & Lmvm & $M V M_{i . t}=\prod^{l=12}\left(1+R_{i, t}\right)-\prod^{l=12}\left(1+M_{m, t}\right)$ \\
\hline Financial risks & Z-score & $Z=0.012 X 1+0.014 \times 2+0.033 \times 3+0.006 X 4+0.999 X$ \\
\hline Coporate innovation & Innovate & R\&D investment/operating income \\
\hline Coporate value & Tobin & Market value/total assets \\
\hline
\end{tabular}


assets ( $\mathrm{R}$ is for individual stocks on a monthly basis)

\subsection{Path Analysis}

In this study, the analysis software AMOS 26.0 was used to construct the model and carry out the specific path analysis. First, build the structural equation model as shown below

$$
\begin{gathered}
\text { tobin }=\alpha_{1} \text { pledge }+\mu_{1} \\
\text { seperate }=\alpha_{2} \text { pledge }+\mu_{2} \\
\text { lmvm }=\alpha_{3} \text { pledge }+\mu_{3}
\end{gathered}
$$

$$
\begin{gathered}
\text { zscore }=\alpha_{4} \text { pledge }+\mu_{4} \\
\text { innovate }=\alpha_{5} \text { pledge }+\mu_{5} \\
\text { tobin }=\alpha_{1} \text { pledg }+\beta_{1} \text { seperate }+\beta_{2} \text { lmvm }+\beta_{3} \text { zscore } \\
+\beta_{4} \text { innovat }+\mu_{6}
\end{gathered}
$$

\begin{tabular}{|c|c|c|c|c|c|}
\hline & Estimate & S.E. & C.R. & $\mathbf{P}$ & label \\
\hline seperate<--- pledge1 & -4.875 & 1.434 & -3.399 & 0.000 & $* * *$ \\
\hline lmvm<--- pledge 1 & 0.288 & 0.238 & 1.210 & 0.226 & \\
\hline zscore<--- pledge 1 & -3.099 & 1.748 & -1.772 & 0.076 & $*$ \\
\hline innovate $<---$ pledge 1 & 1.088 & 0.927 & 1.173 & 0.241 & \\
\hline seperate $<---$ pledge 2 & 21.155 & 3.401 & 6.221 & 0.000 & $* * *$ \\
\hline lmvm<--- pledge 2 & -0.218 & 0.564 & -0.386 & 0.699 & \\
\hline zscore $<---$ pledge2 & -5.947 & 4.146 & -1.434 & 0.151 & \\
\hline innovate $<---$ pledge 2 & -7.522 & 2.199 & -3.421 & 0.000 & $* * *$ \\
\hline tobin<--- seperate & -0.012 & 0.006 & -2.156 & 0.031 & $* *$ \\
\hline tobin<---lmvm & -0.207 & 0.034 & -6.016 & 0.000 & $* * *$ \\
\hline tobin<---zscore & 0.013 & 0.005 & 2.840 & 0.005 & $* * *$ \\
\hline tobin $<-$--innovate & 0.037 & 0.009 & 4.104 & 0.000 & $* * *$ \\
\hline tobin<--- pledge 1 & -1.195 & 0.202 & -5.923 & 0.000 & $* * *$ \\
\hline tobin<--- pledge2 & 1.969 & 0.491 & 4.007 & 0.000 & $* * *$ \\
\hline
\end{tabular}

Notes: $\alpha$ and $\beta$ are the influence coefficients; $\mu$ is the random error term.

Table 2. Test of model fit results

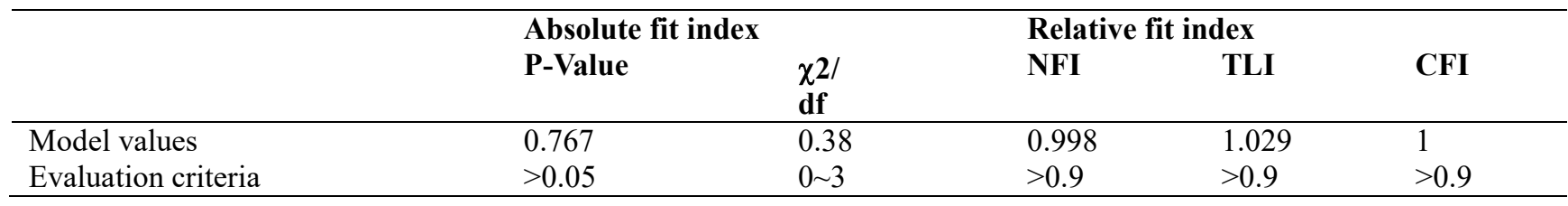

Table 3. Coefficient estimates and results of significance tests for variables

NOTE:*, $* *$ and $* * *$ denote variables significant at the $10 \%, 5 \%$ and $1 \%$ levels, respectively

\subsection{Robustness Tests}

In this study, three sets of robustness tests were carried out to verify the robustness of the model by adopting variable substitution for the relevant variables involved in the above model, including the replacement of market value management indicators, financial risk indicators and enterprise Value Indicator. The results show that the model is robust.

\section{RESULTS AND ANALYSIS}

The degree of pledge has a significant negative impact on the value of the enterprise, which indicates that the more shares the controlling shareholders pledge, the more likely they are to take actions that are detrimental to the value of the enterprise. The indirect way that the degree of pledge affects the value of the enterprise through the separation of the two rights is significantly positive, indicating that the higher the proportion of the shares pledged by the major shareholders in their holdings, the enterprise value can be improved by improving the degree of the separation of the two rights, but the degree of its promotion is not strong. The indirect way that the degree of pledge affects the value of the enterprise through the financial risk is significantly negative, which indicates that the more shares the controlling shareholders pledge, the greater the financial risk the enterprise will face, thus has the negative influence to the enterprise value.

At the same time, the direct impact of pledge scale on enterprise value is significantly positive. The scale of pledge is a relative index of the total share capital of an enterprise. The more shares pledged, but the indirect path that this research explores is: pledge scale -- > separation of two rights -- $>$ Enterprise Value, pledge scale -- > Enterprise Innovation -- > enterprise value, the increase of the scale of the pledge has greatly increased the degree of separation of the two rights and has not brought about the improvement of the innovation ability of the enterprise, so the collateral scale's indirect influence path to the enterprise value is obviously negative. 


\section{SUGGESTION}

The influence of the pledge of controlling equity pledge is complicated. The market parties should not only see the risk caused by the pledge, but also affirm its positive role in easing the financing restriction of enterprises. This study suggests that when controlling shareholders pledge a large proportion of their holdings, even up to $100 \%$ : external investors need to be highly vigilant about this behavior: securities institutions need to carefully consider the feasibility of the implementation of the loan program; Small and medium-sized investors need to carefully consider their investment plans to avoid the risk of large shareholders hollowing out the interests of their enterprises; relevant regulators need to strengthen the supervision of such enterprises, to guard against the self-interest of large shareholders, we should restrict the high proportion of pledge of stock rights by relevant rules and regulations.

\section{CONCLUSION}

From the direct path, equity pledge has a significant impact on corporate value. The degree of pledge has a significant negative impact on the value of the enterprise. When the controlling shareholder pledges its own shares on a large scale, it is likely to mean the controlling shareholder's motive for tunneling, which has a negative impact on the value of the enterprise; From a point of view, the scale of pledge has a significant positive impact on the value of an enterprise, and the behavior of share refinancing solves the capital needs of the enterprise and alleviates the financing constraints it faces, thereby helping to maximize the value of the enterprise.

From the indirect path, the indirect path that equity pledge affects the value of the enterprise through the separation of the two rights is significant. The expansion of the pledge scale has greatly aggravated the degree of separation of the enterprise, and ultimately has a negative impact on the value of the enterprise. The degree of equity pledge affects the value of the enterprise through the indirect path of financial risk is significant. Although there is no pressure to repay the principal and interest of the equity pledge, the risk of forced liquidation after the equity pledge will aggravate the financial risk of the enterprise, which will have a negative impact on the value of the enterprise. The scale of equity pledge has a significant indirect path that affects corporate innovation and corporate value. The scale of pledge has a negative impact on corporate innovation. On the one hand, this may be related to the direction of pledged funds. On the other hand, it may be that major shareholders refuse to maintain stock price stability. Invest funds into activities that are difficult to control for returns and risks such as corporate innovation.

\section{REFERENCES}

[1] X.C. Hao, and Q.Liang, Does the pledge of the ultimate controller's shareholding impair the value of the company?. Accounting Research,vol. 07, pp. 57-63, July 2009. DOI:10.3969/j.issn.1003-2886.2009.07.007

[2] G.J. Zheng, D.J. Lin, and F.D. Zhang, Large shareholders' financial distress, shelling out and the effectiveness of corporate governance - Evidence from large shareholders' financial data. Management World, vol 05, pp 157-168, May 2013.DOI:

CNKI:SUN:GLSJ.0.2013-05-016

[3] B.WANG, A.H.CAI, and Y. FENG, Major shareholders' equity pledges, control transfer risk and firm performance. Systems Engineering Theory and Practice, vol 07, pp 1762-1773, July 2013.DOI: 10.3969/j.issn.1000-6788.2013.07.017

[4] M.Li, C.Liu, and T. Scott, Share Pledges and Firm Value. Pacific-Basin Finance Journal, vol 55, pp 192-205, April 2019 . DOI: 10.1016/j.pacfin.2019.04.001

[5] X.Ling, and Z.T. Wang, A study on equity pledges and corporate value undergrowth opportunity threshold. Finance and Accounting Newsletter, vol 21, pp 77-81, October 2020.

[6] C.Q.Li, W.Xing, and M.L. Li, Controlling shareholders' equity pledges and cash holding levels: "emptying out" or "avoiding the risk of control transfer". Finance and Trade Economics, vol 04, pp 82-98, April 2018. DOI:

CNKI:SUN:CMJJ.0.2018-04-007

[7] G.Y.Mei, F.G.Xiao, and H.J. Xiang. A study on the impact of equity pledges on corporate value [J]. Contemporary Financial Studies, vol 05, pp 99-114, October 2019. DOI: CNKI:SUN:DJRY.0.2019-05-010 